\title{
OBITUARY
}

\section{DAVID BINGHAM OLNEY}

\author{
MBBS LRCP MRCS FRCS FFAEM
}

\begin{abstract}
David Olney was a consultant in accident and emergency medicine at Milton Keynes General since 1988. He died in his sleep on the 26th July 1995, aged 45.

David's initial education took place in Leeds. $\mathrm{He}$ graduated MBBS from Westminster in 1973 and spent a year in Australia working in various surgical specialties, but completed his postgraduate and higher professional training in Yorkshire. He obtained FRCS in 1980.

David was an enthusiast. He was chairman of his local Pastoral Church Council and a keen bridge player. He took an active part in local medical politics and was a member of the BMA executive committee, Milton Keynes branch, and a member of the local negotiating committee. He was chairman of the Regional
\end{abstract}

Accident and Emergency Advisory Committee, a job he did with the utmost dedication and untiring enthusiasm. In this capacity, he stimulated debates and discussions on the acute hospitals of the future. He played a prominent role in the review of acute services in the East Anglia and Oxford Region.

David had a strong sense of purpose. His commitment and dedication to the specialty of Accident and Emergency was second to none. With his untimely death, the A\&E world has been deprived of its exceptionally capable ambassador.

K KUMAR

Clinical Director, AE广E Department Milton Keynes General Hospital

\section{LETTERS TO THE EDITOR}

\section{An undesirable feature in defibrillators}

Sir;- During a recent resuscitation attempt in our emergency room we noted a highly undesirable feature of some equipment.

Most modern defibrillators offer a choice between monitoring from the paddles or a precordial lead. The popular S\&W DMS 730 defibrillator, in common with other S\&W equipment-for example the DMS 750 combined defibrillator and pacer-monitors the ECG through the precordial leads if plugged in and through the defibrillator paddles if not. These machines also have three pins on the front panel which are used to test the ECG display. The precordial lead patient connectors are fastened to these pins and if the system is functioning satisfactorily an internally generated ECG trace showing sinus rhythm at a rate of 60 cycles per minute is displayed.

These pins are not meant to be used as the "resting" position for the patient connectors, but only to demonstrate correct function of the device.

Clearly if these test pins are used as the position of rest for the ECG lead patient connectors a spurious diagnosis of electromechanical dissociation (EMD) is risked. Recently we used one of these S\&W machines and this internally generated signal was mistaken for true EMD by a well drilled team and an experienced team leader.

Clearly a test feature is desirable, but older (600 series) S\&W apparatus used a rectangular waveform for this purpose. A simple change from a very convincing simulation of sinus rhythm to the previous rectangular waveform would mean that the mistake we made could not be repeated. The test pins are widely used as a convenient means of "parking" the patient connectors.

This feature seems not to be widely understood. Any artificial simulation of normality seems a highly undesirable design feature in critical care equipment. The manufacturer tells us that they regard this as an advance over the previous rectangular waveform. We cannot concur.

It seems probable that in our case the outcome was not altered, since the correct diagnosis was asystole, but had the true diagnosis been ventricular fibrillation this "feature" could have cost our patient his life.

$$
\begin{array}{r}
\text { S DERBYSHIRE } \\
\text { A C SKINNER } \\
\text { Department of Anaesthetics, Whiston Hospital } \\
\text { Warrington Rd, Prescot L35 5DR }
\end{array}
$$

Perils of the recovery position: neurapraxia of radial and common peroneal nerve

Sir;- We wish to highlight the risk of developing a combined radial and common peroneal nerve palsy for the patient who is placed in the recovery position for a prolonged time.

A 27 year old male presented to the accident and emergency department com- plaining of left arm and left leg weakness. He woke up that morning to find that he was unable to use his left hand properly and his left foot felt weak. The previous night he had injected heroin in his left forearm and he had been "out" for approximately 12 hours. On examination he was found to be fully alert, normotensive, and all peripheral pulses were normal. There was obvious left wrist and left foot drop. He was unable to extend his left wrist and had a small anaesthetic area on the dorsal aspect of the first web space. He was unable to dorsiflex his left foot and there was altered sensation over the lateral aspect of his left lower leg. All reflexes were normal and he had bilateral downgoing plantar reflexes. There were no other abnormalities. A diagnosis of lower motor neurone palsy of the left radial and the left common peroneal nerve was made, but the mechanism remained unclear.

On taking a detailed history from the patient's friend, it transpired that the patient had suffered an apnoeic episode after injecting heroin. He was placed in the recovery position by his friend as recommended by the Resuscitation Council London, UK. ${ }^{1}$ Upon waking next morning he discovered that he was unable to extend his left wrist, and his left foot was catching the floor. He was managed with splints and physiotherapy and made a complete recovery within three weeks.

Neurapraxia has not previously been reported in association with the recovery position. We report this case of neurapraxia involving two separate nerves that occurred 


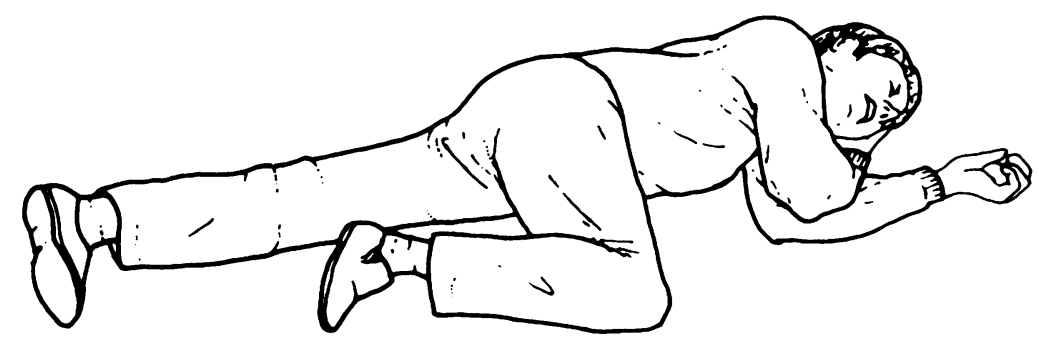

Recovery position showing vulnerability of radial nerve and common peroneal nerve.

after a prolonged time in recovery position. The purpose of the recovery position is to maintain the airway, minimise the risk of aspiration, and ensure that the tongue does not cause airway obstruction. In the recovery position, the head rests on the forearm thereby applying pressure on the radial nerve. Further, in the semiprone position the common peroneal nerve is compressed as it passes around the neck of the fibula. Prolonged compression while the patient lay in the recovery position led to neurapraxia of the two nerves involved. Neurapraxia results from prolonged pressure on a nerve. Morphologically there is intussusception of axon and myelin through the nodes of Ranvier leading to a functional conduction block. ${ }^{2}$ The patient usually makes a complete recovery, as in this case, but motor weakness may be evident for up to three months or even longer.

The recovery position (figure) offers the optimal position for nursing any patient with an impaired level of consciousness who has not suffered trauma. However, a prolonged period in this position is likely to predispose to neurapraxia as seen here. There is also concern that in the recovery position the venous return from the dependent arm may be obstructed. ${ }^{3}$ It is recommended that perfusion and venous drainage of the dependent arm is monitored adequately to minimise the risk of vascular injury. Although the lay public are aware of the recovery position and are encouraged to use it while nursing unconscious patients, their understanding of the possible complications remains limited. If a patient does not make a prompt recovery, it is important for the patient to be sent to hospital for full evaluation, unless the circumstances are both known and understood, for example for certain types of epilepsy. ${ }^{4}$

P KUMAR

$R$ TOUQUET

Accident and Emergency Medicine, St Mary's Hospital, Praed Street,

London W2 $1 \mathrm{NY}$

1 Handley AJ, Swain A, eds. Advanced life support manual, 2nd ed. London: Resuscitation Council, 1994.

2 Castaldo JE, Ochoa JL. Mechanical injury of peripheral nerves. Fine structure and dysfunction. Clin Plast Surg 1984;11:9-16.

3 Fulstow R, Smith GB. The new recovery position, a cautionary tale. Resuscitation 1993;26:88-91.

4 Hunt N, Touquet VLR. Known epileptic patients brought to the accident and emergency department. $\mathcal{f} R$ Coll Gen Prac 1986;36:224-5.

\section{Protective clothing in accident and emergency departments: cost versus risk benefit}

The introduction of protective clothing for Accident and Emergency (A\&E) personnel is suggested by Steedman, ${ }^{1}$ who states that employers should seriously consider the introduction of protective clothing systems to reduce the risks of viral transmission. The concept of protective clothing was supported by Ireland. ${ }^{2}$

In Oxford we also decided that it was inappropriate for our medical and nursing staff to work in traditional clothes. The health risk of soiling of clothes was the main reason promoting a change. Other factors included the medical staff complaining of expensive bills cleaning shirts and trousers soiled with blood, body fluids, and plaster-of-paris. The nurses felt that their uniforms were not ideal for $A \& E$ work in that they did not allow easy movement when lifting. We looked at various options for reclothing the staff members of the A\&E department. Rental of suits similar to those used in Edinburgh would at that time (18 months ago) have cost our department an annual rental fee of approximately $£ 40,000$. We understand that these prices have since decreased. Instead we decided to use much simpler suits in standard theatre fabrics. The cost to the department was less than $£ 5000$ for a once only purchase, although they need regular laundering with its cost implications. This is offset, however, by the savings on laundering nurses uniforms and white coats. These suits are not impermeable to blood and body fluids and do not fully protect the forearms but they can easily be changed if seen to be soiled.

A survey of our nursing and medical staff showed that $100 \%$ of the surveyed staff felt that their new clothing was both more comfortable to wear and allowed them to perform their day to day work with more ease. Patients and staff have also commented that it is now much easier to identify who is actually working in $\mathrm{A} \& \mathrm{E}$ as all our nurses are in blue and the doctors in green, differentiating them from ward staff and other groups in the hospital.

We have sacrificed an element of staff protection for a substantial cost saving. Is this justified? To answer this question one must look at the relative risk of our staff receiving an exposure to a virus that results in seroconversion while wearing the new clothing. Three cases have been reported ${ }^{3}$ where HIV infection has developed in health care workers who had direct contact of blood with the skin but without needlestick exposure. However all of these cases also had skin lesions that may have been contaminated by blood. A survey by Habimana et $a l^{4}$ looked at a particularly high risk group for occupationa exposure to HIV through skin contamination, traditional birth attendants in Rwanda, and estimated that 215 birth attendants tested as HIV negative had received 2234 potentially infectious blood-skin contacts over the previous five years. They found no evidence of HIV infection cased by occupational blood contact. There have been no cases of HIV transmission proven to be secondary to transmission through intact skin alone.

The Management of Health and Safety at Work Regulations 1992, No 2051, section 3, Risk Assessment, ${ }^{5}$ states that every employe shall make a suitable and sufficient assessment of the risks to the health and safety of his employees to which they are exposed while at work. Our staff have been advised that they should observe universal precautions at all times. If their clothing becomes visibly soiled they are advised to wash and change the uniform. If they have any break in their skin it must be covered with a water resistant dressing. No-one with an open wound is allowed to work in the department. If soiling with blood is expected, additional measures should be taken using masks, goggles, and aprons.

We agree wholeheartedly with Steedman that as health care professionals we should protect our staff against possible risks of infection. We endorse fully the published guidelines on health care exposure to HIV and hepatitis transmission. ${ }^{6}$ However, we do not believe that the wearing of clothes impermeable to body fluids is at presen justified on cost grounds when weighed against the clinical evidence of potentia infection through intact skin. We believe our measures to be an appropriate response to the risk of contamination by blood and body fluids and suggest that they allow a better use of a finite budget.

P J HORMBREY
F MOORE
D V SKINNER
Accident and Emergency Department,
Oxford Radcliffe Hospital Trust, Oxford

Steedman DJ. Protective clothing for acciden and emergency personnel. $\mathcal{F}$ Accid Emerg Med 1994;11:17-19.

2 Ireland AJ. Contamination of clothing in accident and emergency departments. $\mathcal{F}$ Accid Emerg Med 1995;12:73.

3 Centre for Disease Control. Update: human immunodeficiency virus infections in health care workers exposed to blood of infected patients. MMWR 1987;36:285-8.

4 Habimana $P$, Bulterys $M$, Usabuwera $P$, Cha A, Saah AJ. A survey of occupational blood A, Saah AJ. A survey of occupational blood birth attenders in Rwanda. AIDS 1994; 8:701-4.

5 Health and Safety Executive. The management of Health and Safety at Work regulations 1992 [N 2051]. London: HMSO, 1992.

6 Joint Working Party of the Hospital Infection Society and the Surgical Infection Study Group. Risk to surgeons and patients from HIV and hepatitis: guidelines on precaution and management of exposure to blood or body fluids. BMF 1992;305:1337-43. 